ments would scarcely justify the conclusions of Freslenthal that trypsin is a nucleo-compound.

The fact that only those solutions were active which gave a positive biuret test would seem to indicate that trypsin is of a proteid nature. However, in some cases the biuret test was scarcely perceptible, and yet the solution of the self-digested trypsin still contained the active ferment.

Experiments on other enzymes in the same direction are now in progress.

I wish to express my indebteduess to Doctor D. Sculley for the assistance received from him.

\title{
CONTRIBUTIONS TO THE KNOWLEDGE OF REVERSIBLE REACTIONS.
}

BY W. N. STLLE.

Received June 17, Igot.

T

$\mathrm{HE}$ object of the study outlined in the following pages was primarily to investigate the positions of the points of equilibrium when acid solutions of certain metals were treated with hydrogen sulphide, and to determine the influence of agitation and temperature upon these points. Incidentally to this main purpose, it was thought desirable to ascertain under what conditions the separation of certain metals, such as zinc and cadmium, could most accurately be effected by hydrogen sulphide. The author has been unable to find any account of accurate determinations upon this latter point, though the common method of separating zinc and cadmium by hydrogen sulphide is practiced in almost all laboratories.

At the beginning it was found that the attainment of equilibrium with acid solutions of zinc and cadmium presented serious difficulties, since the reactions are exceedingly slow, and, in fact, in no case was complete equilibrium reached even after the solution had been treated with a rapid stream of hydrogen sulphide for many hours. As the work advanced, therefore, the importance of the speeds of the reactions became more and more apparent, and as a result this factor became the chief object of study, and incidental thereto, the effects of temperature and agitation.

Since the author must discontinue the work for a time to devote himself to other duties, it is deemed best to publish the results, incomplete as they are, on account of their bearing upon practi- 
cal problems of analysis. At a later date he hopes to continue the work and discuss it with reference to the theory of equilibrium and mass action. Thus far the work has extended only to zinc and cadmium in hydrochloric and sulphuric acid solutions.

Apparatus and Precipitation.-The solution of the metal was contained in two tubes immersed in a water-bath, kept at constant temperature by a thermostat. Washed hydrogen sulphide was passed into the tubes at the rate of about 4 liters per hour. At the end of any period of time selected, a portion was filtered and the zinc or cadmium remaining in solution determined. The zinc was determined volumetrically by the ferrocyanide method of Lyte. Cadmium was determined as the sulphide. When temperatures higher than $30^{\circ}$ were used a tube partially filled with water was placed in the bath and connected between the gas-generator and the precipitation tubes so as to compensate so far as possible for the loss of water from the solution by evaporation.

SERIES I. ZINC IN HYDROCHLORIC ACID SOLUTION.

Column I indicates the number of the determination, II the time in hours, III the per cent. of free hydrochloric acid, and IV the per cent. of zinc remaining in solution. The temperature was $20^{\circ}$.

$\begin{array}{rllc}\text { I. } & \text { II. } & \text { III. } & \text { IV. } \\ \text { I } & 0.5 & 0.06 & 4.3 I \\ 2 & \text { I.0 } & 0.57 & 3.84 \\ 3 & 1.5 & 0.98 & 3.48 \\ 4 & 2.0 & \text { I.53 } & 3.00 \\ 5 & 2.5 & 1.76 & 2.78 \\ 6 & 3.0 & 1.92 & 2.63 \\ 7 & 3.5 & 2.14 & 2.42 \\ 8 & 4.0 & 2.27 & 2.32 \\ 9 & 4.5 & 2.35 & 2.25 \\ \text { IO } & 5.0 & 2.48 & 2.13 \\ \text { II } & 5.5 & 2.65 & \text { I.98 } \\ \text { I2 } & 6.0 & 2.72 & \text { I.92 } \\ \text { I3 } & 6.5 & 2.86 & \text { I.8I } \\ \text { I4 } & 7.0 & 2.98 & \text { I.69 } \\ \text { I5 } & 7.5 & 3.18 & \text { I.55 }\end{array}$

It will be observed that at the end of seven and one.half hours, precipitation was still taking place and at a rate which indicated that equilibrium was yet far removed. 
SERIES II, ZINC IN SULPHURIC ACID SOLUTION.

The conditions of precipitation were the same as in Series I. Here, as in Series I, the zinc sulphide precipitated was perfectly white, the zinc used being a very pure specimen that showed no impurity save a trace of iron, and an amount of carbon residue too small for determination. Column II shows the time in hours, column III the per cent. of free sulphuric acid, and IV the amount of zinc remaining in solution.

$\begin{array}{lcll}\text { I. } & \text { II. } & \text { III. } & \text { IV. } \\ \text { I } & 0 & \text { I.09 } & 2.29 \\ 2 & \text { I } & 2.12 & 1.60 \\ 3 & 2 & 2.65 & 1.25 \\ 4 & 3 & 3.40 & 0.75 \\ 5 & 4 & 3.95 & 0.38 \\ 6 & 5 & 4.26 & 0.18 \\ 7 & 6 & 4.38 & 0.07 \\ 8 & 7 & 4.47 & 0.03\end{array}$

At the end of seven hours precipitation was still going on, although very nearly complete. The solution contained about 4.50 per cent. of free acid. In order the better to compare the restraining action of the two acids, it was thought desirable to use solutions which would contain approximately the same amounts of zinc at the beginning and at the end of the precipitation. The results are shown in Series III.

SERIES III. ZINC IN SULPHURIC ACID SOLUTION.

$\begin{array}{llll}\text { I. } & \text { II. } & \text { III. } & \text { IV. } \\ \text { I } & \text { I } & 0.95 & 4.24 \\ 2 & 2 & \text { I.76 } & 3.68 \\ 3 & 3 & 2.28 & 3.35 \\ 4 & 4 & 2.88 & 2.94 \\ 5 & 5.5 & 3.49 & 2.54 \\ 6 & 6.5 & 3.77 & 2.35 \\ 7 & 7.5 & 4.18 & 2.08 \\ 8 & 9.0 & 4.6 I & \text { I.80 } \\ 9 & \text { I0.5 } & 5.25 & \text { I.37 }\end{array}$

The course of the reaction in the presence of free sulphuric acid is very similar to that in the presence of free hydrochloric acid. The curves representing time and precipitation in the two cases are very nearly parallel. Comparing the amounts of free acids at the end of equal times (seven and one-half hours) in Series I and III, it may be observed that sulphuric acid exerts little less re- 
straining influence than hydrochloric, since the amount of the former exceeds the latter by only about i per cent.

Influence of Time.-It seemed desirable to determine the influence of time, if any, upon the amount of precipitation, and to this end four experiments were performed with the same solution. In the following table, column II gives the time during which the gas was passed into the solution, column III the time in hours that the solution was allowed to stand before filtering, IV the free hydrochloric acid, and $V$ the zinc remaining in solution. In 3 the solution was shaken one and one-half hours before filtering. Of course the tubes were kept tightly stoppered while standing. At the ends of the respective times the solution still contained much free hydrogen sulphide.

$\begin{array}{llc}\text { SERIES IV. } & & \\ \text { III. } & \text { IV. } & \text { V. } \\ \text { O } & 2.82 & \text { I.83 } \\ \text { I2 } & 3.1 \mathrm{Ir} & \mathrm{I} .57 \\ \text { I3.5 } & 3.10 & 1.57 \\ \text { I3.5 } & 3.87 & 0.89\end{array}$

The results show some precipitation after the hydrogen sulphide has been stopped, but probably a three-sided equilibrium of hydrogen sulphide, hydrochloric acid, and zinc chloride is reached within a few hours, and this does not seem to be affected by agitation.

Influence of Agitation.-In order to determine more fully the effect of agitation upon the rate of precipitation, portions of a solution containing 4.86 per cent. of free and combined hydrochloric acid were treated in two tubes, with hydrogen sulphide. In one of these tubes was a stirrer kept in rapid motion by a hotair engine. The tubes were kept at the same temperature, $20^{\circ}$. Column V shows the amounts of zinc remaining in solution in the tube not provided with a stirrer, at the ends of the respective periods, and column IV gives the zinc in the solution stirred. In order to reduce the effect of agitation due to the gas itself, the rate of flow was made considerably less than that used in the other series.

\begin{tabular}{ccccc}
\multicolumn{5}{c}{ SERIES V. } \\
I. & II. & III. & IV. & V. \\
I & I & 4.86 & 3.53 & 3.65 \\
2 & 2 & $\ldots$. & 2.85 & 2.80 \\
3 & 3 & $\ldots$ & 2.15 & 2.23 \\
4 & 4 & $\ldots .01$ & 1.73 & 2.01
\end{tabular}


The results confirm that of experiment 3 , in Series IV, and show that agitation has very little influence upon the rate of precipitation.

Influence of Temperature.-To determine the influence of temperature upon the rate of precipitation, portions of the same solution of zinc chloride were treated at $20^{\circ}$ and $50^{\circ}$, respectively, for five hours with hydrogen sulphide flowing at the same rate in each case. Column II, in Series VI, gives the temperature, column III the time, and column IV the zinc remaining in solution. The results show that change in temperature within moderate limits has very little influence upon either the rate of precipitation or the point of final equilibrium.

\begin{tabular}{|c|c|c|c|}
\hline \multicolumn{4}{|c|}{ SERIES VI. } \\
\hline I. & II. & III. & IV. \\
\hline I & $20^{\circ}$ & 5 & I. $4 \mathrm{I}$ \\
\hline 2 & $50^{\circ}$ & 5 & 1.49 \\
\hline
\end{tabular}

Cadmium.-A solution of cadmium chloride was made by dissolving the pure metal in hydrochloric acid. It contained 9.47 per cent. of cadmium and the total acid was II.33 per cent. The solution gave a pure yellow precipitate with hydrogen sulphide which was free from zinc. The only impurity found was a trace of iron. This solution was treated with hydrogen sulphide in the same way as those of zinc. At the ends of the periods chosen portions were filtered and the cadmium remaining in solution was determined as sulphide, with the usual precautions. In the following table column II contains the time in hours, column III the per cents. of free acid, and IV the per cents. of cadmium remaining in solution.

SERIES VII.

$\begin{array}{lcrc}\text { I. } & \text { II. } & \text { III. } & \text { IV. } \\ \text { I } & 2 & 8.72 & 4.00 \\ 2 & 3 & 9.40 & 2.96 \\ 3 & 4 & 9.84 & 2.42 \\ 4 & 5 & 10.15 & 1.8 \mathrm{I} \\ 5 & 7 & 10.19 & 1.75 \\ 6 & 8 & 10.26 & 1.64\end{array}$

The general trend of the curve of precipitation is the same as that for the precipitation of zinc from a solution of the chloride, as may be seen by a comparison of the above results with those of Series I, though the approximate equilibrium in the case of cad- 
mium is reached much sooner. A comparison of the two is of interest from the analytical point of view. Zinc is by no means all precipitated after many hours from a solution containing 3.I8 per cent. of free hydrochloric acid, and the precipitation of cadmium is not complete in a solution containing I0.26 per cent. of this acid. The range of the strength of acid within which it might be considered possible to separate the two metals by precipitation with hydrogen sulphide is, therefore, considerably less than 7 per cent., and a consideration of the curves would lead one to doubt whether it is possible to separate them by a single precipitation with any strength of hydrochloric acid.

Cadmium in Sulphuric Acid Solution.-Cadmium sulphate was made by heating pure cadmium nitrate with pure concentrated sulphuric acid until all trace of nitric acid had disappeared. Experiments showed that cadmium could be completely and quickly precipitated at $20^{\circ} \mathrm{C}$. from any strength of sulphuric acid solution. Attention was directed, therefore, to its precipitation at higher temperatures, and for this purpose $85^{\circ}$ was the point chosen as convenient. A solution containing about 15 per cent. of free acid and 9 per cent. of cadmium sulphate was treated with hydrogen sulphide at the usual rate for three and a half hours. The cadmium remaining in 13 grams of the solution at the end of this time was only 0.0004 gram, while the amount of free acid as shown by titration was 18.66 per cent.

A second solution containing 9 per cent. of cadmium sulphate and 20 per cent. of free acid was treated with hydrogen sulphide for three hours and at $85^{\circ}$. The cadmium remaining in solution was found to be about the same as above, or only a trace, showing that this metal can be practically completely precipitated from a hot solution containing 22.8 per cent. of free sulphuric acid, this being the amount found by direct titration.

By a comparison of these results with those obtained in Series III, zinc sulphate, it will be seen that while the precipitation of zinc had practically ceased when the free sulphuric acid had reached 5.25 per cent., cadmium is totally precipitated at $85^{\circ}$ in the presence of 23 per cent. of free acid. In other words the range of possible complete separation of zinc and cadmium when sulphuric acid is used is at least $I 7$ per cent., or three times what it is when hydrochloric acid is used, and with precipitation at common room temperature the range would probably be much greater. 
In view of the fact that cadmium sulphide is soluble in dilute boiling sulphuric acid, the common method of separating cadmium and copper being based upon this fact, it was deemed rather surprising that complete precipitation had taken place at such a high temperature and in the presence of such a quantity of free acid. The following experiment makes clear this seeming anomaly: A portion of the solution, in the last experiment with cadmium sulphate, which contained only a trace of cadmium immediately after the stream of hydrogen sulphide was stopped, was left in contact with the precipitated cadmium sulphide at $85^{\circ}$ for half an hour. At the end of that time the solution, now almost free from the odor of hydrogen sulphide, had dissolved r.8 per cent. of its weight of cadmium sulphide. This result in connection with what has preceded seems to show that the complete precipitation of cadmium as sulphide depends chiefly upon the saturation of the solution with hydrogen sulphide, the temperature and strength of the acid being of only secondary importance. Direct experiment showed that when pure washed cadmium sulphide is allowed to remain in contact with cold dilute sulphuric acid (2o per cent. $\mathrm{H}_{2} \mathrm{SO}_{4}$ ) for several hours, it is to a very marked degree dissolved.

I wish to take this opportunity to express my sincere thanks to Dr. W. S. Hendrixson, at whose suggestion this work was undertaken and to whose kind advice and aid any success which this little study may have attained is largely due.

IOWA COLLEGE, GRINNELL,

June 10, 1901.

\section{NEW BOOKS.}

Atoms and Energies. By D. A. Murray. New York : A. S. Barues \& Co. 1901. $202 \mathrm{pp}$. Illus. $12 \mathrm{mo}$.

The author of this book was some time instructor in the Government Shogyo Gakko, Kyoto, Japan, and he is at present pastor of a Church in a Western city. He claims that the " changed conceptions of the nature of fundamental atomic phenomena" presented in this book, must create a "complete revolution in our thinking along many lines of physical research," and for those who accept his visionary lucubrations this claim will certainly be justified.

According to the author, atoms are all identical in substance 